\title{
Effect of friction stir welding on hydrogen content of ISO 3183 X80M steel
}

\author{
J. J. Hoyos $^{1 *}$, V. F. Pereira ${ }^{1}$, R. R. Giorjao ${ }^{1}$, T. R. McNelley ${ }^{2}$, A. J. Ramírez ${ }^{1,3}$ \\ ${ }^{1}$ Metals Characterization and Processing Laboratory (CPM), Brazilian Nanotechnology National Laboratory (LNNano), National \\ Research Center for Energy and Materials (CNPEM). Campinas, SP 13083-970, Brazil. *Corresponding author. Tel: +55 1935183115. \\ E-mail: john.hoyos@Innano.cnpem.br \\ ${ }^{2}$ Department of Mechanical and Aerospace Engineering, Naval Postgraduate School, Monterrey, CA 93940 U.S.A. \\ ${ }^{3}$ Department of Materials Science and Engineering, Ohio State University, Columbus, OH 43210 U.S.A.
}

\begin{abstract}
The influence of Friction Stir Welding (FSW) on hydrogen content of ISO 3183 X80M high strength steel was evaluated for several welding conditions, including dry and underwater environments. The diffusible and non-diffusible (residual) hydrogen were measured by a hot extraction method that involved adaptation of ISO 3690 and AWS A4.3 (arc welding process) standards. It was found that FSW does not significantly influence the hydrogen content under dry conditions even when the steel surface is oxidized. A slight increase in both diffusible and residual hydrogen content was observed for underwater FSW. However, the total hydrogen content is significantly less than the minimum allowable hydrogen concentration in similar steels. In addition, the low tool temperature reached during underwater FSW suggests the absence of hydrogen generation by water molecule decomposition. This is in according with the temperature distribution in water obtained by finite element method simulation of this welding process. Therefore, FSW is a feasible welding process and offers important advantages in terms of hydrogen control when it is compared to conventional fusion welding processes.
\end{abstract}

Key words: FSW; High strength steel; Diffusible hydrogen; Underwater welding; Hot extraction method 


\section{INTRODUCTION}

High-strength steels are used in a wide range of marine applications, including commercial and naval vessels as well as off-shore platforms [1, 2]. These steels are also used in pipelines, which are the most economical and safe way of gas and oil transportation [3-5]. Therefore, it is necessary to assure the highest level of mechanical performance through the improvement of material processing and joining techniques. Currently, joining of these steels is performed mostly by fusion welding. This leads to problems related to melting and solidification such as porosity, liquation, solidification cracking, and hydrogen induced cracking (HIC) [6]. HIC is one of the main problems encountered in the welding of high strength steels $[7,8]$.

The implementation of Friction Stir Welding (FSW) technology with these steels will enable the replacement of fusion welding process in selected cases. This will lead to productivity improvements, cost reduction, and better mechanical performance. FSW is a solid state process involving a severe thermomechanical cycle induced by a rotating, non-consumable tool [9-11]. Nevertheless, the implementation of FSW will require demonstration that the diffusible and residual hydrogen levels of welded joints are indeed lower in comparison to conventional process and, furthermore, within acceptable limits for appropriate materials and conditions.

There have been few investigations of the hydrogen concentrations in steels following FSW or the allied technology of Friction Stir Processing (FSP). Moreover, there is no agreed procedure for the measurement of diffusible and residual hydrogen in association with these welding or processing techniques. Young [1] and Overfield [2] reported residual hydrogen concentrations of plates of high strength steels processed by FSW/P (bead-on-plate runs) in air and underwater environments.

In both investigations [1, 2], the residual hydrogen concentrations of base metal and welding samples were within the acceptable range of the relevant MILSPEC (2.0-5.5 $\mathrm{ml} \mathrm{H}_{2} / 100 \mathrm{~g}$ metal) [12]. In addition, the hydrogen concentrations after dry welding are lower in comparison to wet welding. This may reflect higher temperatures and a more prolonged thermomechanical cycle during dry welding, thus enabling diffusion and removal of hydrogen. However, the materials were not degassed before welding and thus the initial hydrogen concentrations were significantly 
different. This generates some differences in the results. In HY-80 steel [1], the dry welding sample contains the lowest hydrogen content whereas in AISI 4142 steel [2], the base metal contains the lowest hydrogen content.

The current work examines the feasibility of FSW under several conditions for ISO 3183 X80M steel. The diffusible hydrogen content of welded samples joined by FSW was measured following procedures adapted from the ISO 3690:2012 [13] and AWS A4.3 1993 [14] standards. Whereas underwater FSW were simulated by finite element method to obtain the temperature distribution of steel and water, suggesting the absence of the decomposition of water molecule, and the subsequent hydrogen generation. It was found that FSW does not have a significant influence on the hydrogen concentration in ISO 3183 X80M steel.

\section{MATERIALS AND METHODS}

Samples of $80 \mathrm{~mm} \times 25 \mathrm{~mm} \times 12 \mathrm{~mm}$ of the ISO $3183 \times 80 \mathrm{M}$ steel (table 1) were divided into two groups. In the first, the samples were degassed at $650{ }^{\circ} \mathrm{C}$ for 1 hour in a protective atmosphere, and then were subject to FSW under three different conditions (dry, under fresh water and under salt water). In the second, the samples were heated at $650{ }^{\circ} \mathrm{C}$ for 1 hour without protective atmosphere, and then were dry welding. The microstructure was observed by optical microscopy, etching with $2 \%$ nital solution. The iron oxide film of non-degassed samples was characterized by X-Ray Diffraction (XRD) at room temperature, using $\mathrm{CoK}_{\alpha}$ radiation.

The ISO 3690:2012 [13] and AWS A4.3 1993 [14] procedures for determination of diffusible and residual hydrogen concentrations were incorporated into FSW procedures. The test piece assembly (central piece, and run-on and run-off tabs) was aligned and fixed to a clamping device during welding. After welding, it was cooling in an ice water and a liquid nitrogen baths in order to avoid the hydrogen release, and then the central piece was broken off from the tabs, and stored under nitrogen liquid until the hydrogen content measurements. No attempt was made to prevent hydrogen absorption during welding although flowing argon was used to protect the Polycrystalline Boron Nitride (PCBN) tool against oxidation during dry and oxidized welding runs. The PCBN tool shoulder diameter was $25 \mathrm{~mm}$ and the conical pin was $6 \mathrm{~mm}$ long with a step spiral feature. 
All welding runs were conducted at $300 \mathrm{rpm}$ spindle speed and $100 \mathrm{~mm} / \mathrm{min}$ travel speed. The axial force was $16 \mathrm{KN}, 24 \mathrm{KN}$ and $30 \mathrm{KN}$ for dry, oxidized and underwater welding runs, respectively. For underwater welding, the test piece assembly was immersed in a stainless steel container filled with water and ice, and equipped with the water inlets in the front of the PCBN tool and outlets on one side of the container. The water inlets at $4{ }^{\circ} \mathrm{C}$ and $0.05 \mathrm{~m}^{3} / \mathrm{s}$.

The hydrogen content was measured by the hot extraction method. The detection limit of the equipment is $10^{-4} \mathrm{ml} \mathrm{H}_{2} / 100 \mathrm{~g}$, and the precision is $5 \times 10^{-2} \mathrm{ml} \mathrm{H}_{2} / 100 \mathrm{~g}$. The measurements were made at $400{ }^{\circ} \mathrm{C}$ (diffusible hydrogen) and $900{ }^{\circ} \mathrm{C}$ (residual hydrogen) for 40 minutes with three repetitions. Hydrogen concentration determinations were based on bulk mass $\left(m_{T}\right)$ for non-welded samples and stirred zone mass $\left(m_{S Z}\right)$ for welded samples. The $m_{S Z}$ is estimated from the equation 1, where $A_{S Z}$ and $A_{T}$ are the average cross-sectional areas of the stir zone and the central piece, respectively. These areas were measured from the fracture locations where the tabs had been removed and image analysis of photographs of these locations (figure 1). The same density and thickness are assumed for the stir zone and the central piece.

$m_{S Z}=\left(\begin{array}{ll}A_{S Z} & \\ & A_{T}\end{array}\right) m_{T}$

In addition, dry and underwater FSW were simulated by finite element method. The test piece assembly was replaced by one only piece of $240 \mathrm{~mm} \times 25 \mathrm{~mm} \times 12 \mathrm{~mm}$ in size (figure 2). For underwater FSW, two stainless steel containers were simulated. The first one is $240 \mathrm{~mm} \times 25 \mathrm{~mm}$ $\times 100 \mathrm{~mm}$, and the second one is $240 \mathrm{~mm} \times 25 \mathrm{~mm} \times 80 \mathrm{~mm}$.

The heat generation between the tool and work metal was simulated in transient heat transfer regime (equation 2). Where $\rho$ is the material density, $C_{p}$ is the heat capacity specifies, $T$ is the temperature, $u$ is the material velocity, $k$ is the thermal conductivity, $S_{\text {in }}$ (equation 3 ) is the heat generation term in the interface and $S_{b}$ (equation 4) is the heat rate generated per unit volume due to plastic deformation, $\delta$ is the relative ratio between friction and strain $(0.3), \eta$ is the mechanical efficiency $(0.9), T_{Y}$ is the shear stress $(90 \mathrm{Ksi}), \mu_{\mathrm{f}}$ is the friction coefficient $(0.3), \mathrm{p}_{\mathrm{r}}$ is the pressure applied in the area $\left(75 \mathrm{~N} / \mathrm{mm}^{2}\right), \omega$ is the tool rotating speed, $r$ is the radial distance from the tool 
axis, $v$ is the welding speed, $A$ is the area, and $\beta$ is the plastic deformation fraction dissipated as heat [15-17].

$$
\begin{aligned}
& \rho C_{p} \partial T / \partial t=-\rho C_{p} u \nabla T+k \nabla T+S_{i n}+S_{b} \\
& S_{i n}=\left((1-\delta) \eta \tau_{Y}+\delta \mu_{f} p_{r}\right)(\omega r-v \sin \theta) d A \\
& S_{b}=2 \beta \mu_{f} \sum_{i=1}^{3}\left(\partial u_{i} / \partial x_{i}\right)^{2}+\left(\partial u_{1} / \partial x_{2}+\partial u_{2} / \partial x_{1}\right)^{2}+\left(\partial u_{1} / \partial x_{3}+\partial u_{3} / \partial x_{1}\right)^{2}+\left(\partial u_{3} / \partial x_{2}+\partial u_{2} / \partial x_{3}\right)^{2}
\end{aligned}
$$

$S_{\text {in }}$ takes in account two contributions: the heat generated due to friction and due to interfacial deformation next to the tool [18]. The first one is the product of the frictional force and sliding velocity of the material. The second one is the product of the shear stress and the speed of the material that adheres to the tool while this is moving. When the workpiece material adheres to the tool, the heat is generated in the contact piece tool due to shear deformation [16].

\section{RESULTS}

Figure 3 shows the surface of a central piece after diffusible hydrogen measurements. Visual inspection made before these measurements verified the integrity of the welded joints. There were no superficial defects such as surface lack of fill, scalloping or galling, nor were there superficial discontinuities such as cracking, porosity, undercut or underfill. The iron oxide film on the oxidized samples was determined to be $\mathrm{Fe}_{2} \mathrm{O}_{3}$ from analysis of the diffraction data of figure 4 .

Figure 5 shows the microstructure of the base metal and underwater welded joint. In the base metal, the inclusions are orientated on the lamination direction. This preferential orientation is vanished in the stir zone, indicating that FSW process produces a redistribution of the inclusions. During welding, the microstructural change from ferrite (base metal) to bainite (stir zone), as indicated by Hermenegildo [19]. In addition, a grain refinement is also observed, especially in the high temperature heat-affected zone. 
Figure 6 shows the hydrogen measurements. The hydrogen concentration in the degassed material is just above the detection limit $\left(10^{-4} \mathrm{ml} \mathrm{H}_{2} / 100 \mathrm{~g}\right)$. Comparison of the data for degassed material to that for dry FSW of this material reveals that FSW results in an apparent increase in hydrogen concentration but the increase is within the standard error and thus the change cannot be deemed significant. On the other hand, conducting FSW underwater does lead to a slight increase in both diffusible and residual hydrogen concentration. However, all concentrations measured are significantly less than the most conservative allowable limit of diffusible hydrogen for high-strength steels given in MILSPEC [10]. The relation $1 \mathrm{ml} \mathrm{H}_{2} / 100 \mathrm{~g}=0.89$ wt. ppm hydrogen was used for this steel [20].

Figures 7 to 9 show the results obtained for the simulation of FSW. The temperature reached in the stirred zone is near to $1000{ }^{\circ} \mathrm{C}$ for all cases. The increase of the water volume decrease the heating zones, and increase the cooling rate. In dry welding, the cooling rate is $25^{\circ} \mathrm{C} / \mathrm{s}$, while in the underwater welding is $80^{\circ} \mathrm{C} / \mathrm{s}$ and $100^{\circ} \mathrm{C} / \mathrm{s}$ for the small and large stainless steel container, respectively. The tool temperature obtained for the simulation is similar to that measured during welding runs, and the test piece assembly experiences a more prolonged thermomechanical cycle during dry welding in comparison to underwater welding (figure 10). The results obtained for dry welding are in according with that obtained by Hermenegildo [19]. Whereas the temperature distribution in water is in according with the temperature measured in water near to the piece assembly test (from $4{ }^{\circ} \mathrm{C}$ to $17^{\circ} \mathrm{C}$ ). The temperature of the water is significant lower than that required for the water molecule decomposition (figure 11).

FSW has a minimal effect on the hydrogen concentration in the oxidized samples. Nevertheless, the measurements of non-diffusible hydrogen at $900{ }^{\circ} \mathrm{C}$ suggest than the nondegassed, and the oxidized and welded samples both exhibit slightly higher residual hydrogen concentrations when compared to the oxidized samples. Although this increase is within the experimental error, could reflect that the oxide layer behaves as a barrier to the hydrogen exit from the steel. Similarly, the results in dry welding obtained by Young [1] suggest that the FSW reduces the hydrogen content of non-degassed samples, which could be relevant in repairs applications involving of steels used at high temperatures or in corrosive environments. 
The potential use of FSW in repair applications will require understanding of the effects of oxides and other surface contamination on hydrogen pickup. There is no information in this regard. During hydrogen charging, the iron oxide film behaves as a barrier to hydrogen ingress. However, imperfections such as cracks in the oxide layer and reactions involving the oxide film can facilitate the hydrogen input, as discussed by Bruzzoni and Garavaglia [21].

\section{DISCUSION}

The ISO 3690:2012 [13] and AWS A4.3 1993 [14] standards can be adapted to FSW process. Nevertheless, some requirements must to be satisfied. In first place, the clamping device has to resist forces and torques that are not involved in the fusion welding process, and allows a

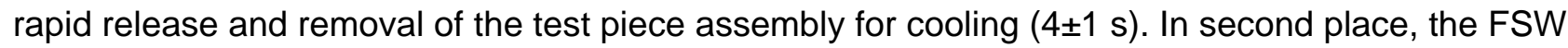
plunge was initiated on the run-on tab at a location $50 \mathrm{~mm}$ from the central piece to assure a steady-state condition during welding of the central portion of the test piece assembly. Although this run length is higher than the recommended for the AWS A4.3 1993 [14], it is according with the ISO 3690:2012 [13]. In third place, the hydrogen concentration calculations are based on the stir zone mass since FSW process does not use filler metal and this zone is analogous to the fused metal weld for autogenous welding process.

Similar to conventional process, it is assumed that the hydrogen pickup mainly takes place by the stir zone. However, it can takes place by both the stir zone and the base metal. This assumption is based on the experimental procedure. In first place, the samples were degassed before welding, obtaining the lowest level of hydrogen on base metal. In second place, the cooling on ice water and liquid nitrogen baths avoids the diffusion of hydrogen, and its subsequent redistribution from the stirred zone to other zones. In conventional process, it is considered that the $90 \%$ of the hydrogen pickup belongs to the fusion welding process, and the $10 \%$ remaining belongs to the base metal $[13,14]$. In order to avoid underestimation of the hydrogen concentration on welded samples, it is assumed that the hydrogen pickup only belongs to the stir zone.

All samples exhibit low hydrogen concentrations. Except for the data for underwater FSW, the values of diffusible hydrogen concentration are within the precision of measurement of the hot 
extraction method. Furthermore, the hydrogen concentrations (both diffusible hydrogen and nondiffusible, i.e., residual hydrogen) in all welding conditions are significantly less than the most conservative allowable limit of diffusible hydrogen for high-strength steels given in MILSPEC [12].

The lower hydrogen input during FSW in comparison to conventional process is attributed to the absence of sources such as filler metal and process temperatures below the melting point. This results in reduced generation of hydrogen as well as lower hydrogen solubility and diffusivity. Usually, hydrogen goes into the material during arc welding by the dissociation, in the arc atmosphere, of hydrogen or its compounds followed by dissolution and diffusion of monoatomic hydrogen into the weld metal and then into the base metal during the welding thermal cycle [14]. Furthermore, the low tool temperatures and the water temperature near to the test piece assembly when conducting FSW underwater, suggest the absence of hydrogen production through decomposition of the water molecule. This is in according with the results obtained for the simulation of FSW.

The slight increase of the hydrogen concentration during underwater welding could be associated to the release of hydrogen from microstructures features such as matrix-inclusion interfaces. The severe deformation and corresponding refinement of the microstructure and redistribution of the inclusions during the FSW thermomechanical cycle may be more effective than annealing alone in release of hydrogen. The temperature reached in the stirred zone $\left(1000^{\circ} \mathrm{C}\right)$ is higher than the annealing temperature $\left(650^{\circ} \mathrm{C}\right)$. Shorter dwell times and more rapid cooling rates during underwater FSW would restrict diffusion leading to retention of more of this hydrogen in the material. In contrast, the test piece assembly experiences a more prolonged thermomechanical cycle during dry welding, allowing more time for removal of hydrogen by diffusion. In that sense, the FSW could contribute to the release of residual hydrogen from microstructure tramps, but the rapid cooling rate during underwater restrict the hydrogen diffusion.

\section{CONCLUSIONS}

The ISO 3690 (2012) and AWS 4.3 (1993) procedures can be adapted to measure the hydrogen concentration in weld joints made by FSW. It was found that the FSW does not 
significantly increase the diffusible and residual hydrogen concentration in ISO 3183 X80M high strength steel under dry welding conditions. The hydrogen pickup during FSW is not increased when the steel surfaces are oxidized. In addition, the hydrogen concentrations attained during FSW under fresh water and under salt water are still significantly less than the most conservative allowable limit for diffusible hydrogen. On the other hand, the water and low tool temperatures reached during underwater FSW suggest that there is not hydrogen generation by water molecule decomposition. This is in according with the results obtained for the simulation of FSW by finite element method. Therefore, FSW reduces the risk of HIC in comparison to conventional fusion welding processes.

\section{ACKNOWLEDGMENTS}

The authors are grateful to the Company USIMINAS for supply the steel and the chemical composition data. The authors J. J. Hoyos, V.F. Pereira, R. R. Giorjao and A. J. Ramírez are grateful to Petrobras, CNPq (Project 455275/2013-0 and 403530/2014-8) e CAPES (Project Instituto Nacional de Ciência, Tecnologia e Inovação em Materiais Complexos Funcionais, Inomat) for financial support. T.R. McNelley acknowledges prior financial support of the US Office of Naval Research.

\section{REFERENCES}

[1] Young G. Feasibility of underwater friction stir welding of hardenable alloy steel. M.S. thesis. Naval Postgraduate School. 2012

[2] Overfield N. Feasibility of underwater friction stir welding of hardenable alloy steel. M.S. thesis. Naval Postgraduate School. 2010.

[3] Bruschi R, Vitali L, Marchionni L, Parella A, Mancini A. Pipe technology and installation equipment for frontier deep water projects. Ocean Engineering 2015; 108:369-392.

[4] Ghajar R, Mirone G, Keshavarz A. Ductile failure of X100 pipeline steel - Experiments and fractography. Mater. Design 2013; 43:513-525. 
[5] Zhang J, Sun W, Sun H, Mechanical Properties and Microstructure of X120 Grade High Strength Pipeline Steel. J. Iron. Steel. Res. Int. 2010; 17-10:63-67.

[6] Santos TFA, Hermenegildo TFC, Alfonso CMR, Marinho RR, Paes MTP, Ramirez AJ. Fracture toughness of ISO 3183 X80M (API 5L X80) steel friction stir welds. Eng. Fract. Mech 2010; 77:2937-2945.

[7] Magudeswaaran G, Balasubramanian V, Madhusudhan G. Effect of welding processes and consumables on fatigue crack growth behaviour of armour grade quenched and tempered steel joints. Defence Technology 2014; 10:47-59.

[8] Shi X, Yan W, Wang W, Shan Y, Yang K. Novel Cu-bearing high-strength pipeline steels with excellent resistance to hydrogen-induced cracking. Mater. Design 2016; 92:300-305.

[9] El-Batahgy A.M, Miura T, Ueji R, Fujii H. Investigation into feasibility of FSW process for welding $1600 \mathrm{MPa}$ quenched and tempered steel. Mater. Sci. Eng. A 2016; 651:904-913.

[10] Nandan N, DebRoy T, Bhadeshia HKDH. Recent advances in friction-stir welding - Process, weldment structure and properties. Prog. Mater. Sci 2008; 53:980-1023.

[11] Gibson B.T, Lammlein D.H, Prater T.J, Longhurst W.R, Cox C.D, Ballun M.C, Dharmaraj K.J, Cook G.E, Strauss A.M. Friction stir welding: Process, automation, and control. J. Manuf. Process 2014; 16:56-73.

[12] Military Specification. 1994. MIL-E-23765/2E 10.

[13] ISO 3690:2012. Welding and allied processes-Determination of hydrogen content in arc weld metal. 2012.

[14] AWS A4.3-93 1993. Standard methods for determination of the diffusible hydrogen content of martensitic, bainitic, and ferritic steel weld metal produced by arc welding. 1993.

[15] Antonino T. De S, Guimarães P.B, Alécio R. De A, Yadava Y.P, Ferreira R.A.S, Measurements of the Thermophysical Properties of the API $5 \mathrm{~L}$ X80. Materials Sciences and Applications 2014; 5 8:617-627.

[16] Nandan R. Computational modeling of heat transfer and visco-plastic flow in friction stir welding. Doctoral thesis. The Pennsylvania State University. December, 2008.

[17] Schmidt H. B, Hattel, J. H. Thermal modelling of friction stir welding. Scripta Materialia 2008; 58 5:332-337. 
[18] Nandan R, et al. Three-dimensional heat and material flow during friction stir welding of mild steel. Acta Materialia 2007; 55 3:883-895.

[19] Hermenegildo T. Soldagem por Atrito com Pino não Consumível do Aço de Alta Resistência ISO 3183 X80M. Doctoral thesis. Universidade Stadual de Campinas. February, 2012.

[20] Maroef I. Hydrogen trapping in ferritic steel weld metal. Int. Mater. Rev 2002; 47:191-223.

[21] Bruzzoni P, Garavaglia R. Anodic iron oxide films and their effect on the hydrogen permeation through steel. Corros. Sci 1992; 33 11:1797-1807. 
Table 1. Chemical composition of ISO 3183 X80M Steel.

Figure 1. Stir zone and base metal in the cross section of the welded joint.

Figure 2. Model designed in finite element software for the study in the water tank (left) and Model after application of the mesh (right).

Figure 3. Surface of a central piece after diffusible hydrogen measurements.

Figure 4. XRD diffractograms of the degassed and welded samples.

Figure 5. Microstructure of the base metal and underwater welding joint. Distribution of inclusions on base metal (a) and welded joint (b), and microstructures of the base metal (c), Low temperature heat-affected zone (d), High temperature heat-affected zone (e), and stir zone (f).

Figure 6. Hydrogen measurements of ISO 3183 X80M high strength steel.

Figure 7. Temperature distribution in test piece assembly during dry welding

Figure 8. Temperature distribution of the test piece assembly and water for underwater welding with the small container.

Figure 9. Temperature distribution of the test piece assembly and water during underwater welding, using the large container.

Figure 10. Tool temperature and thermomechanical cycle during dry and underwater welding.

Figure 11. Temperature distribution of the water during underwater welding, using the large container (steady state). 


\section{Stir zone .}

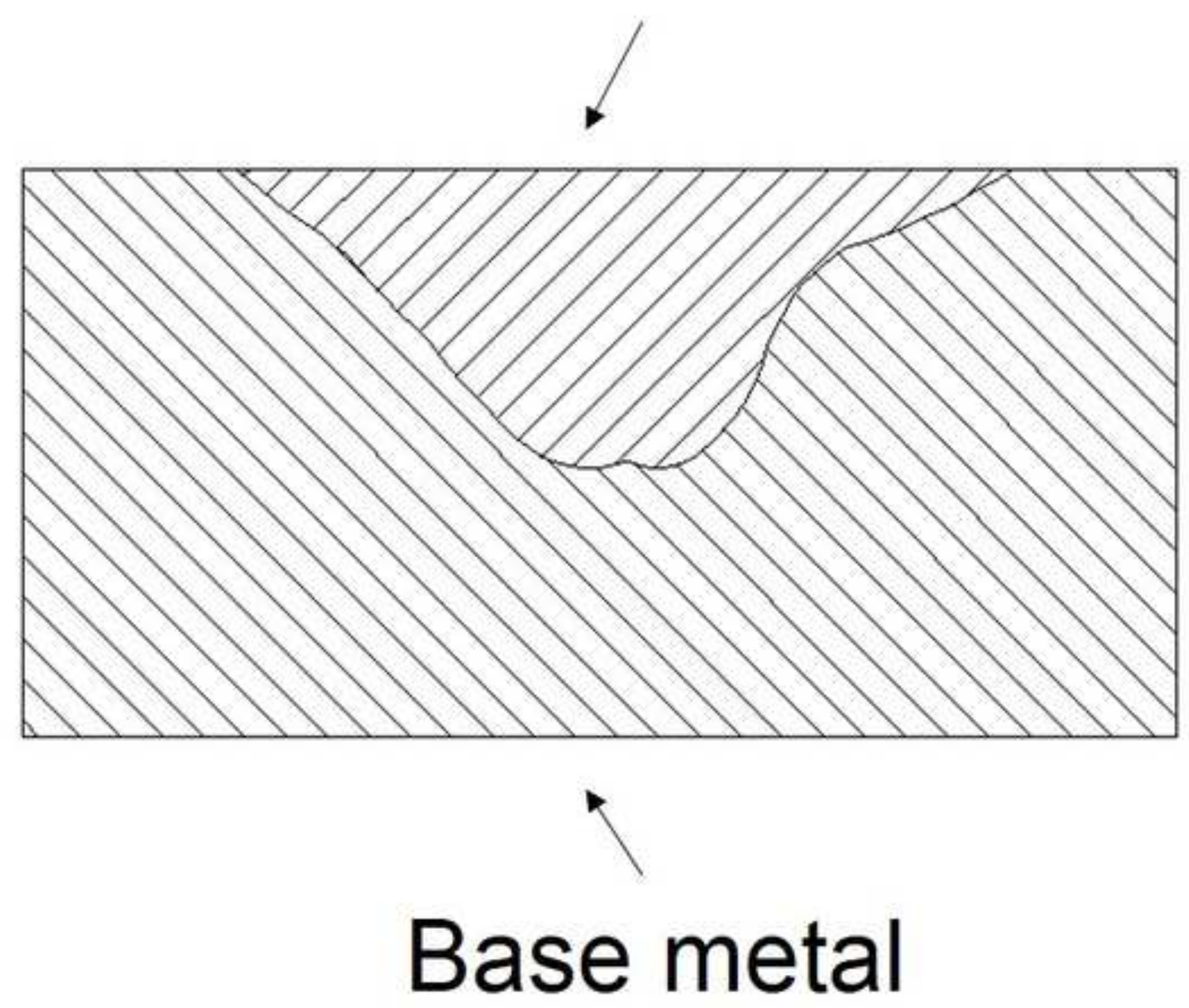

$\checkmark$

Base metal 


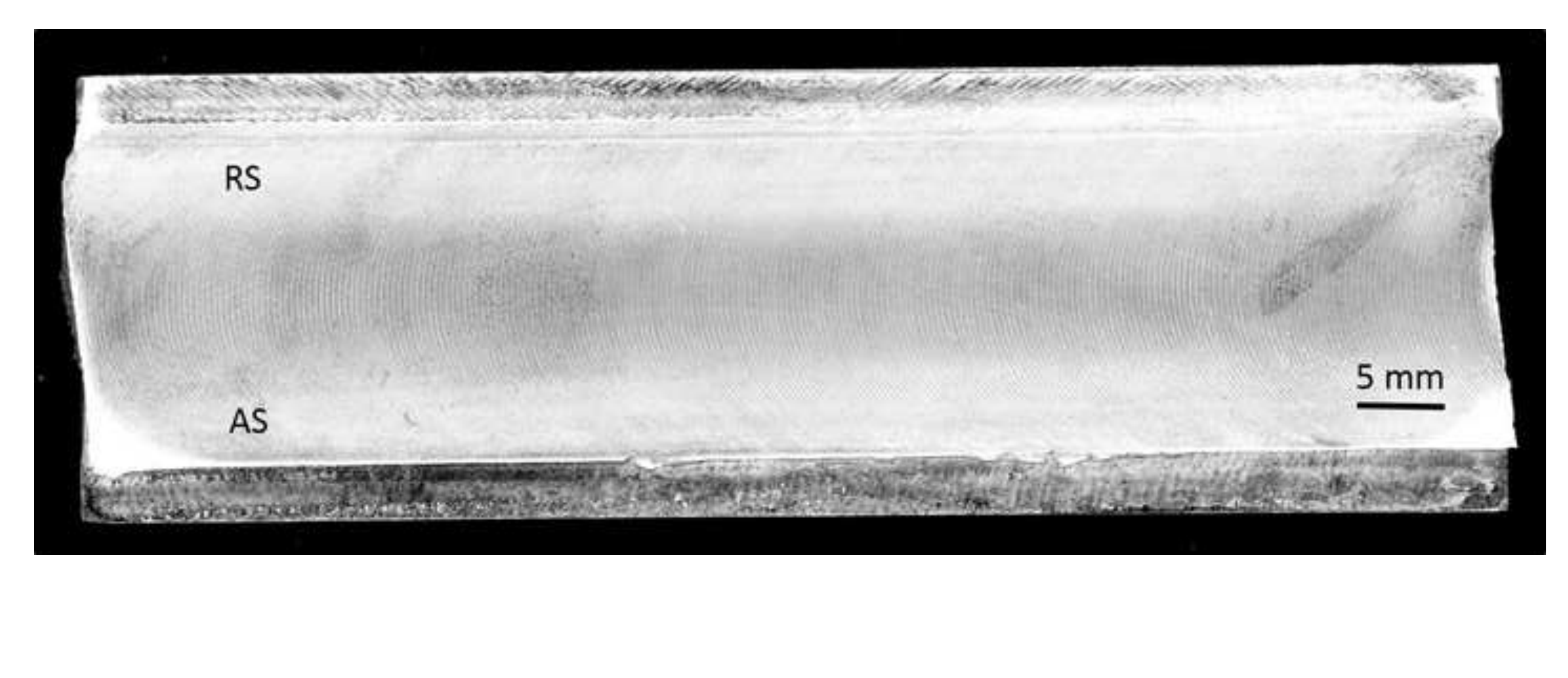

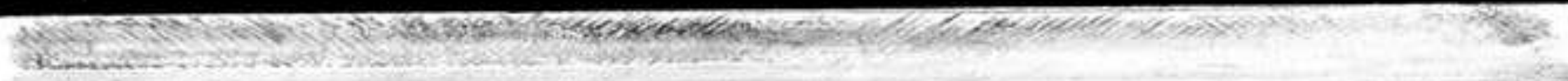

RS

$5 \mathrm{~mm}$

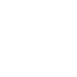

.
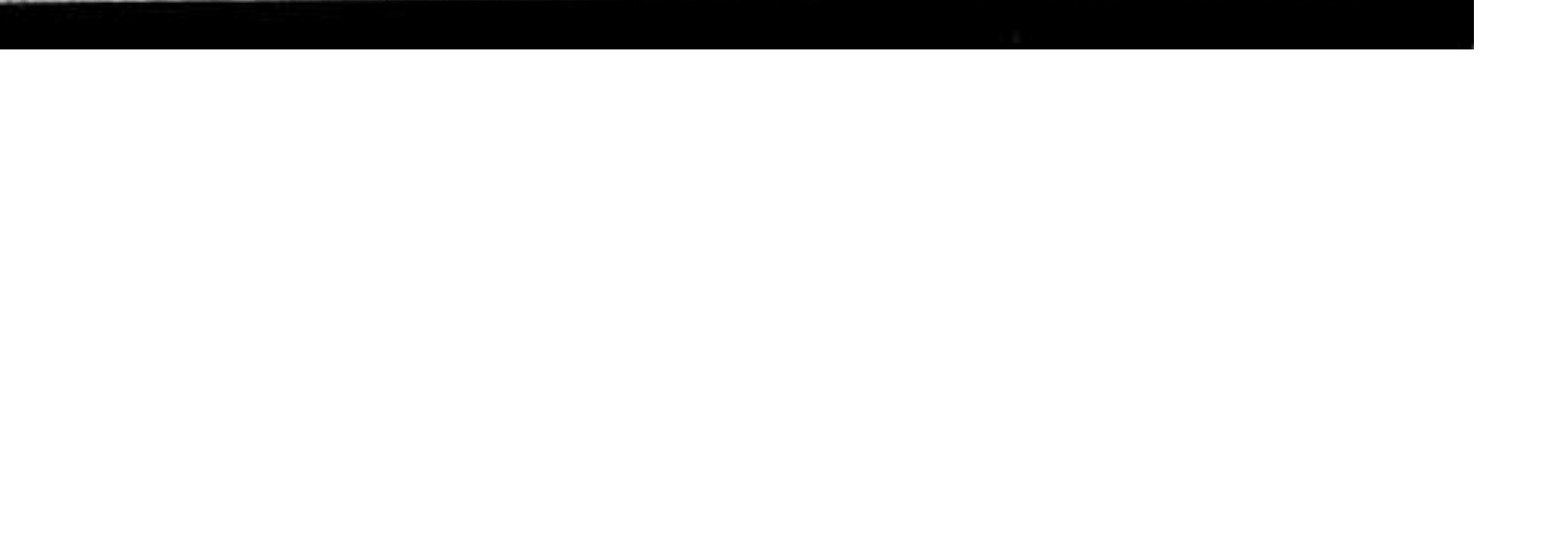


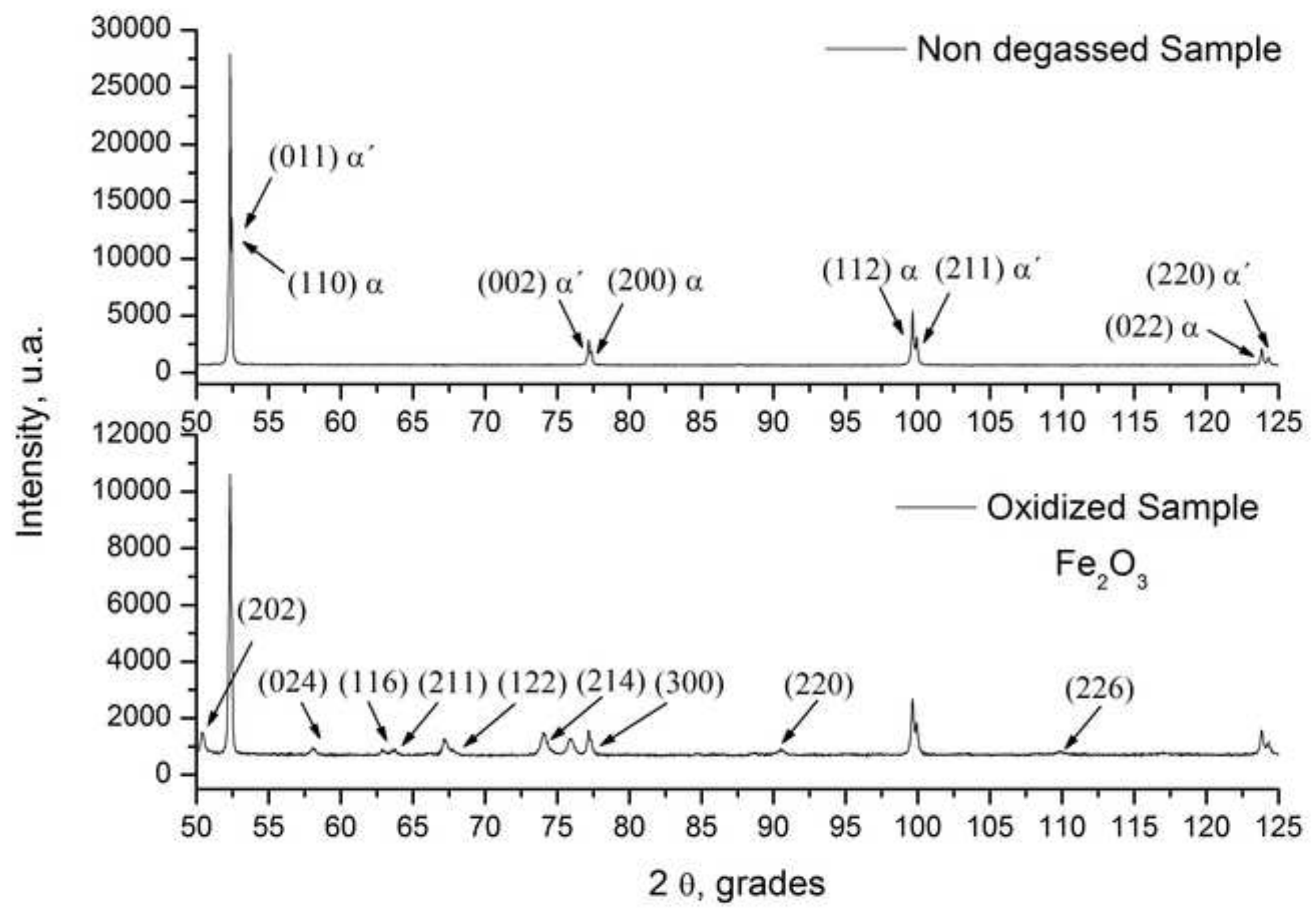


BASE METAL

$2000 \mu \mathrm{m}$

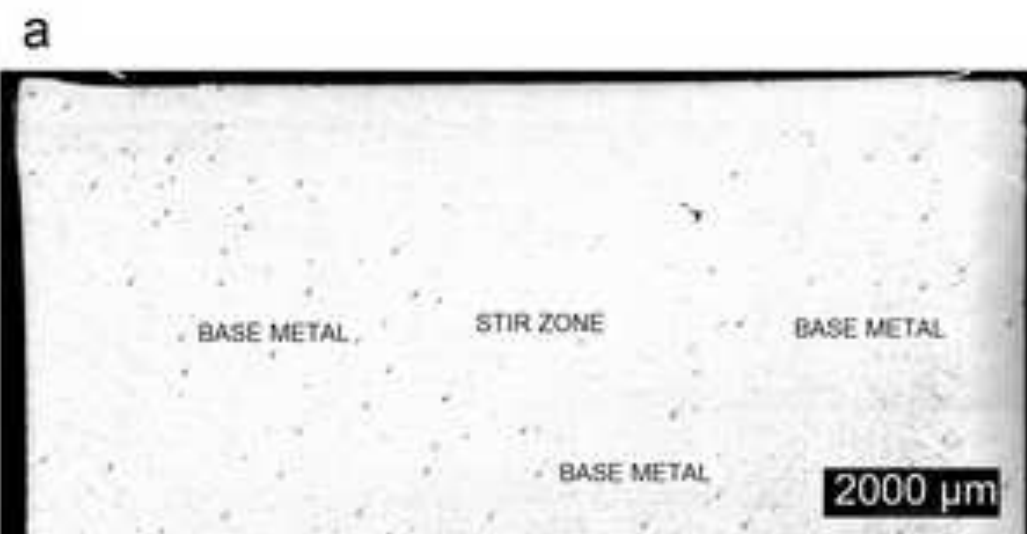

b

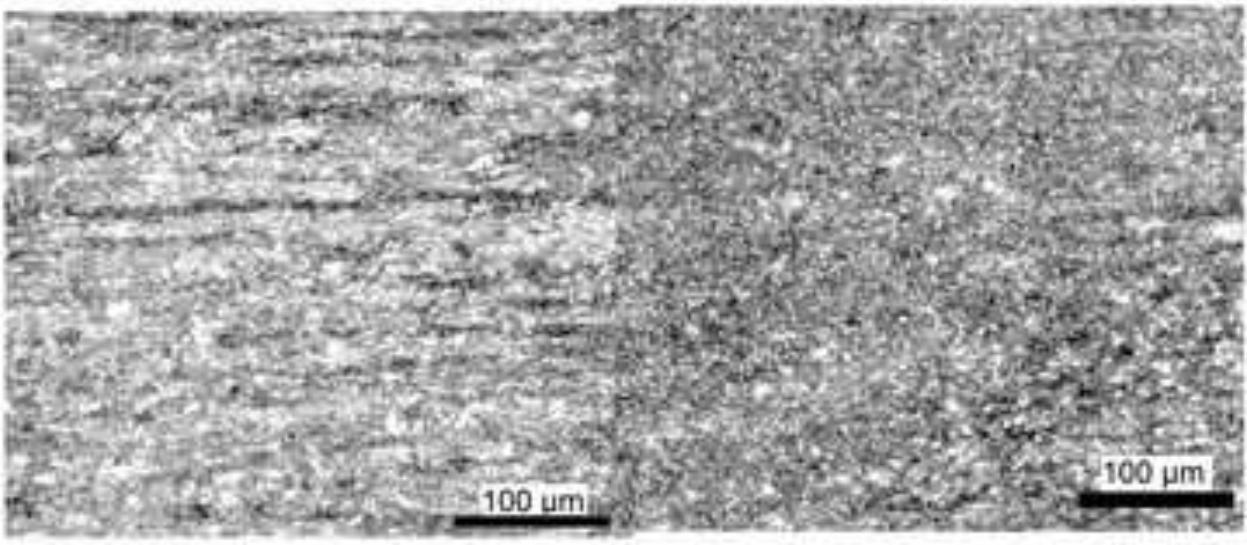

C

d

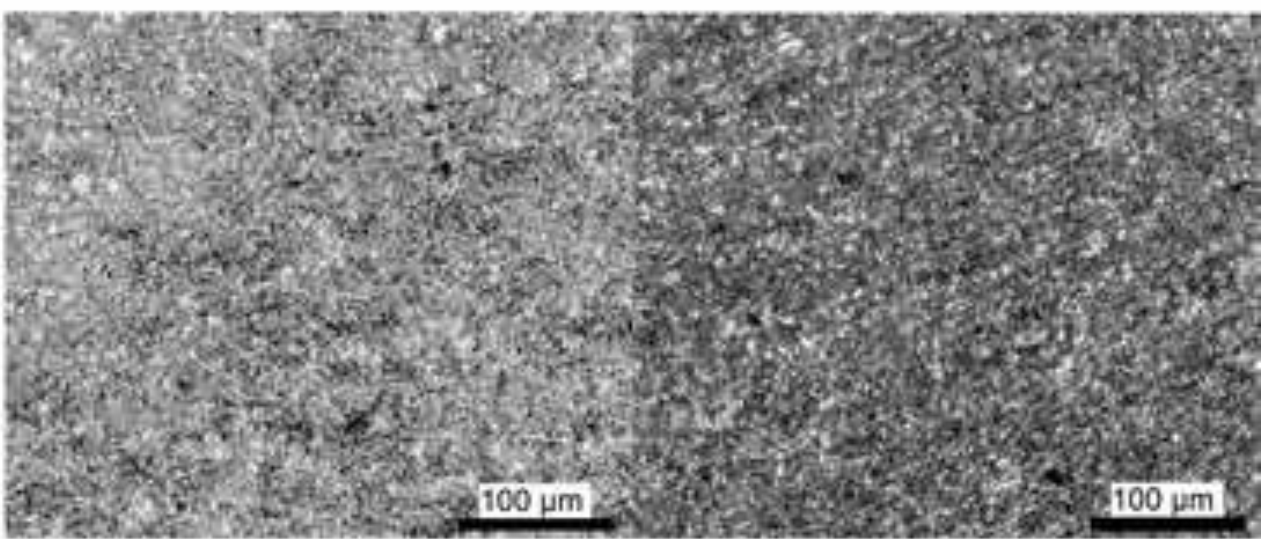

e 


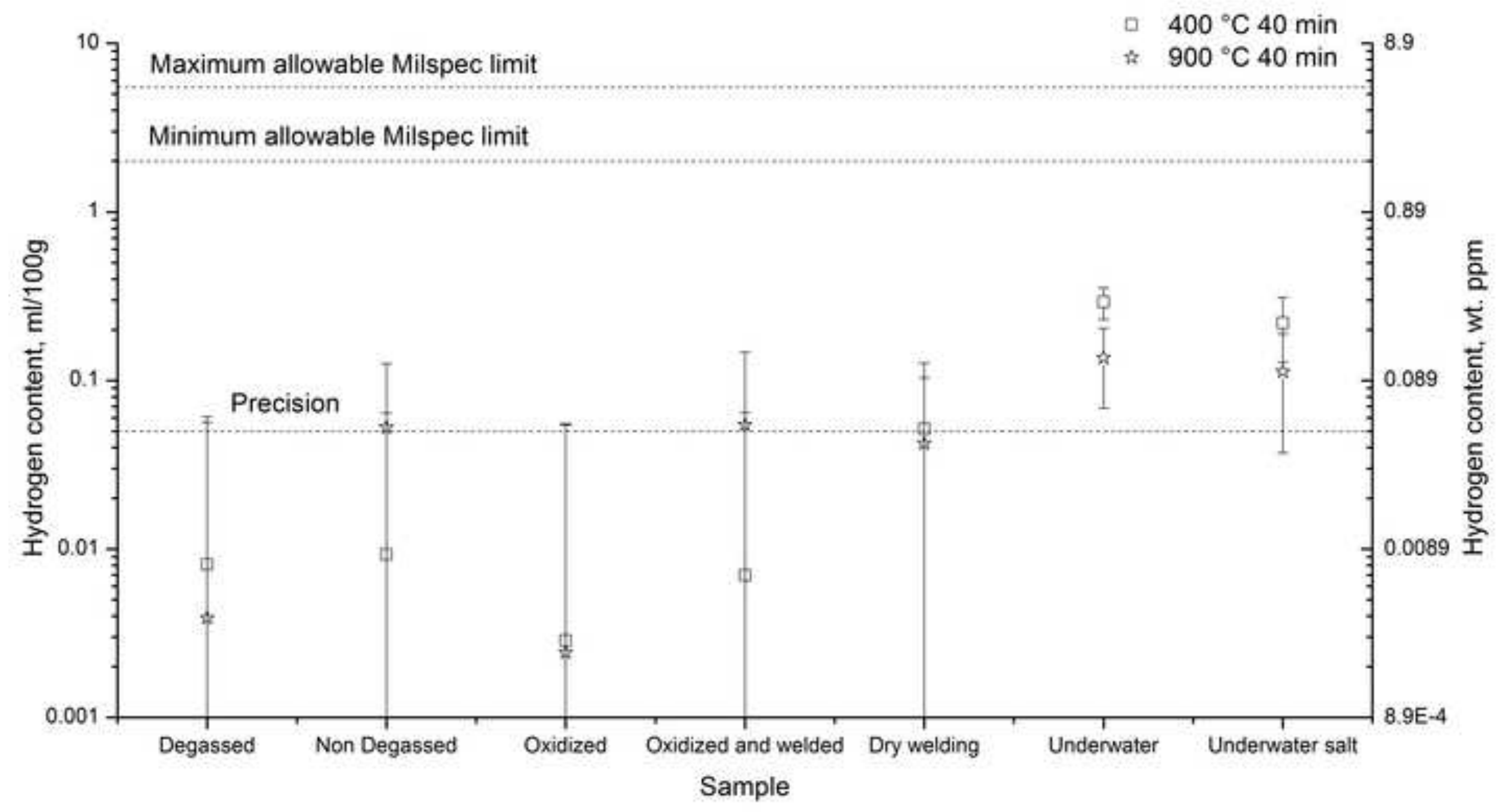




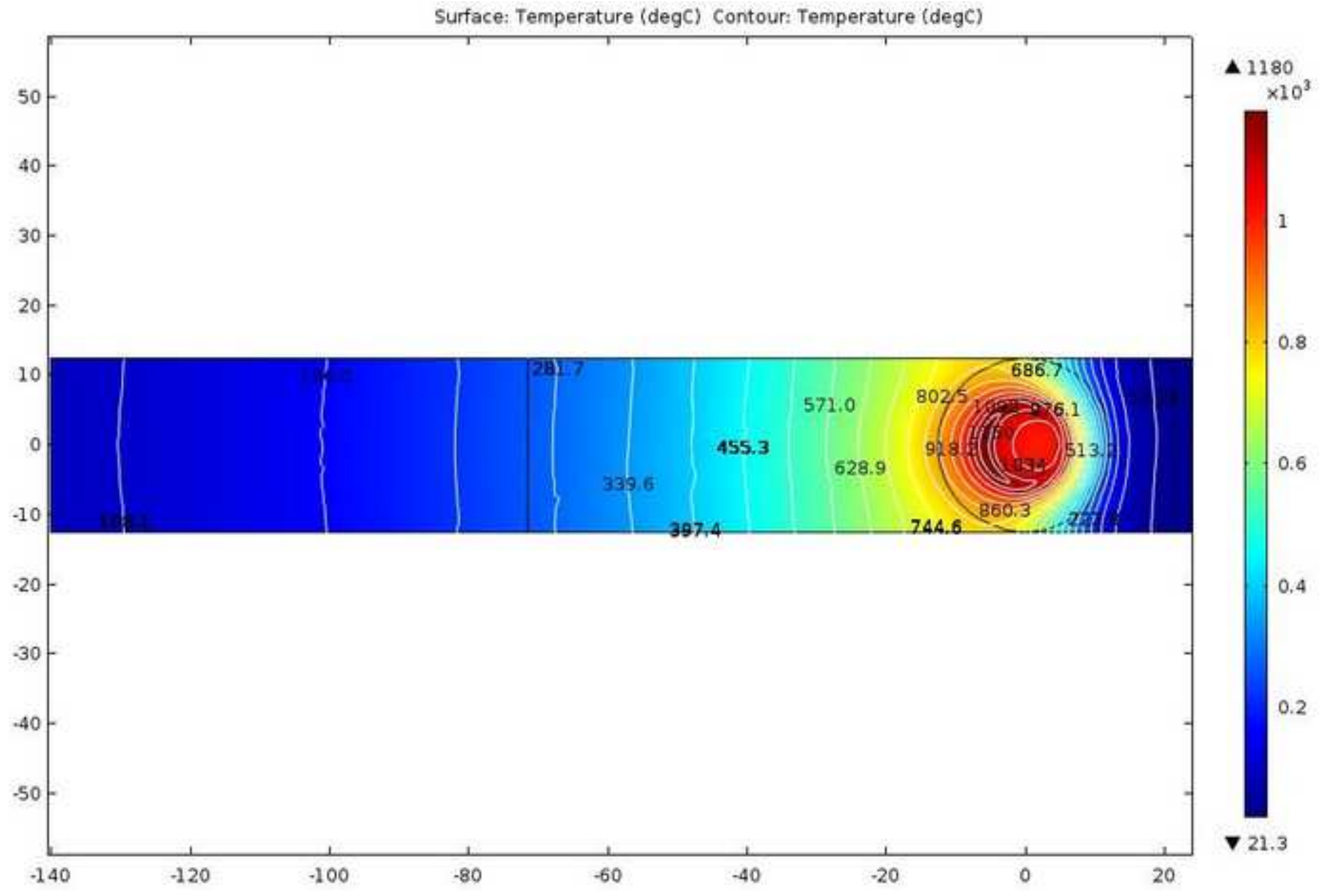

Surface: Temperature (degC) Contour: Temperature (degC)

$-100$ 


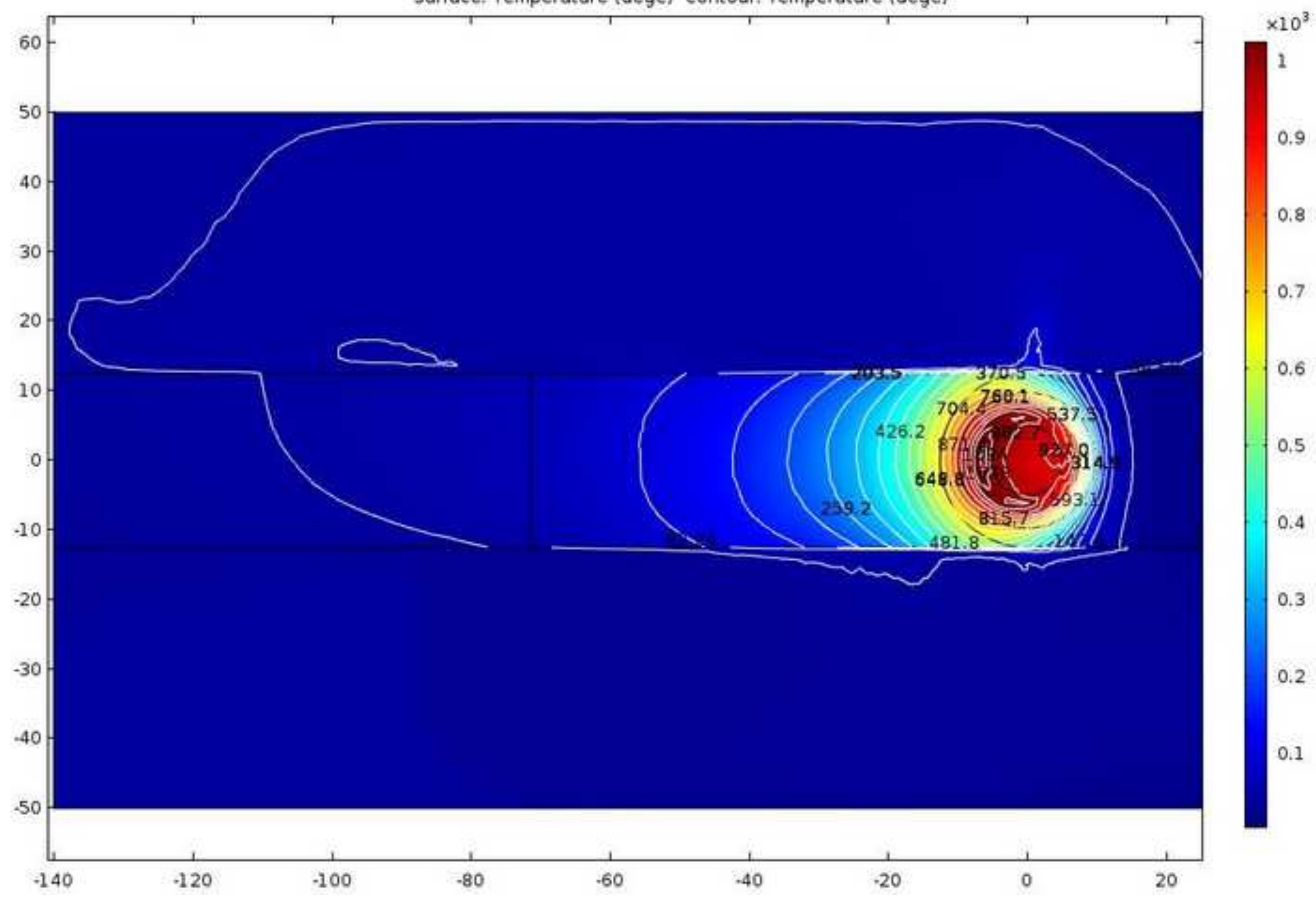




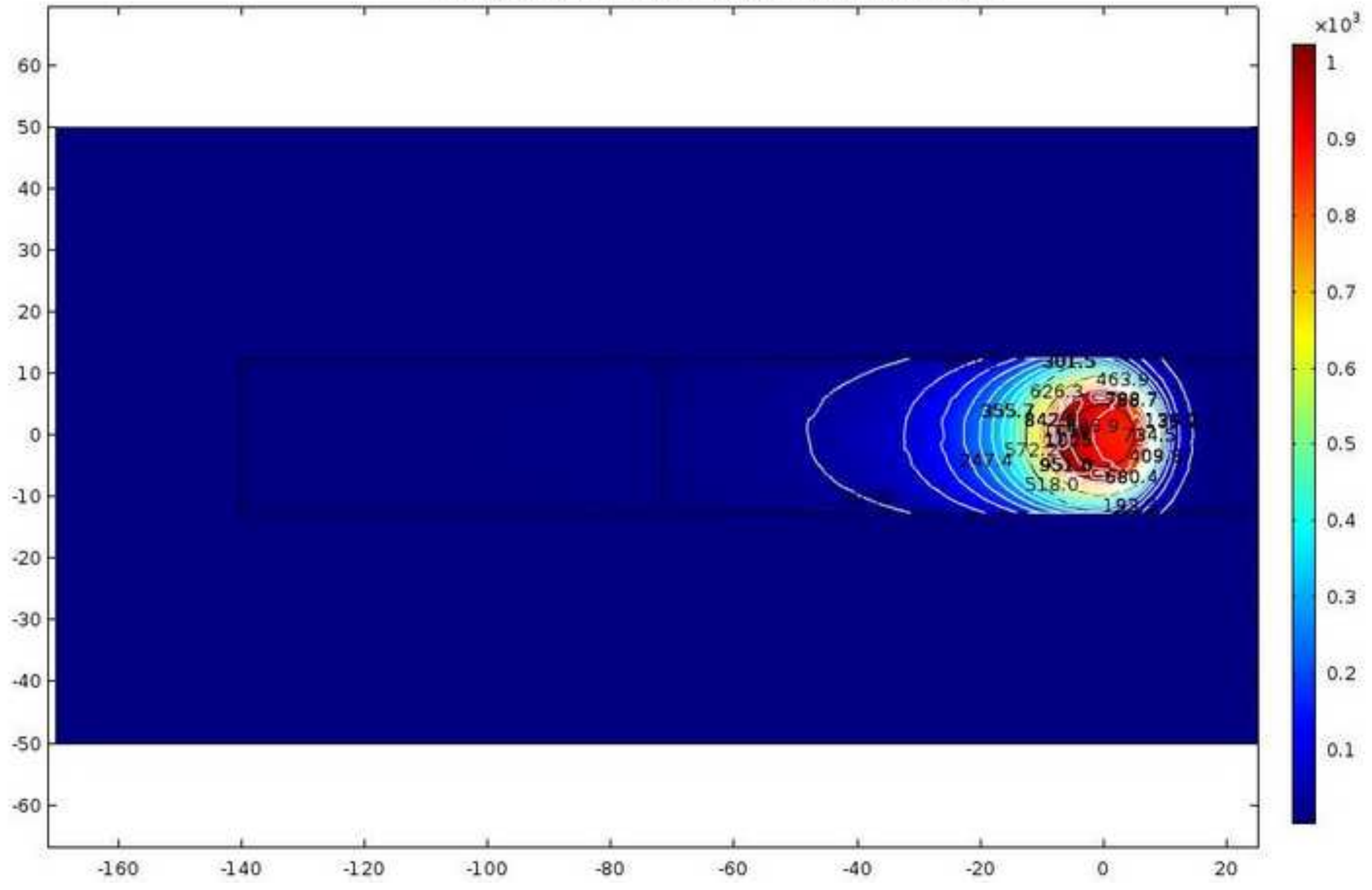




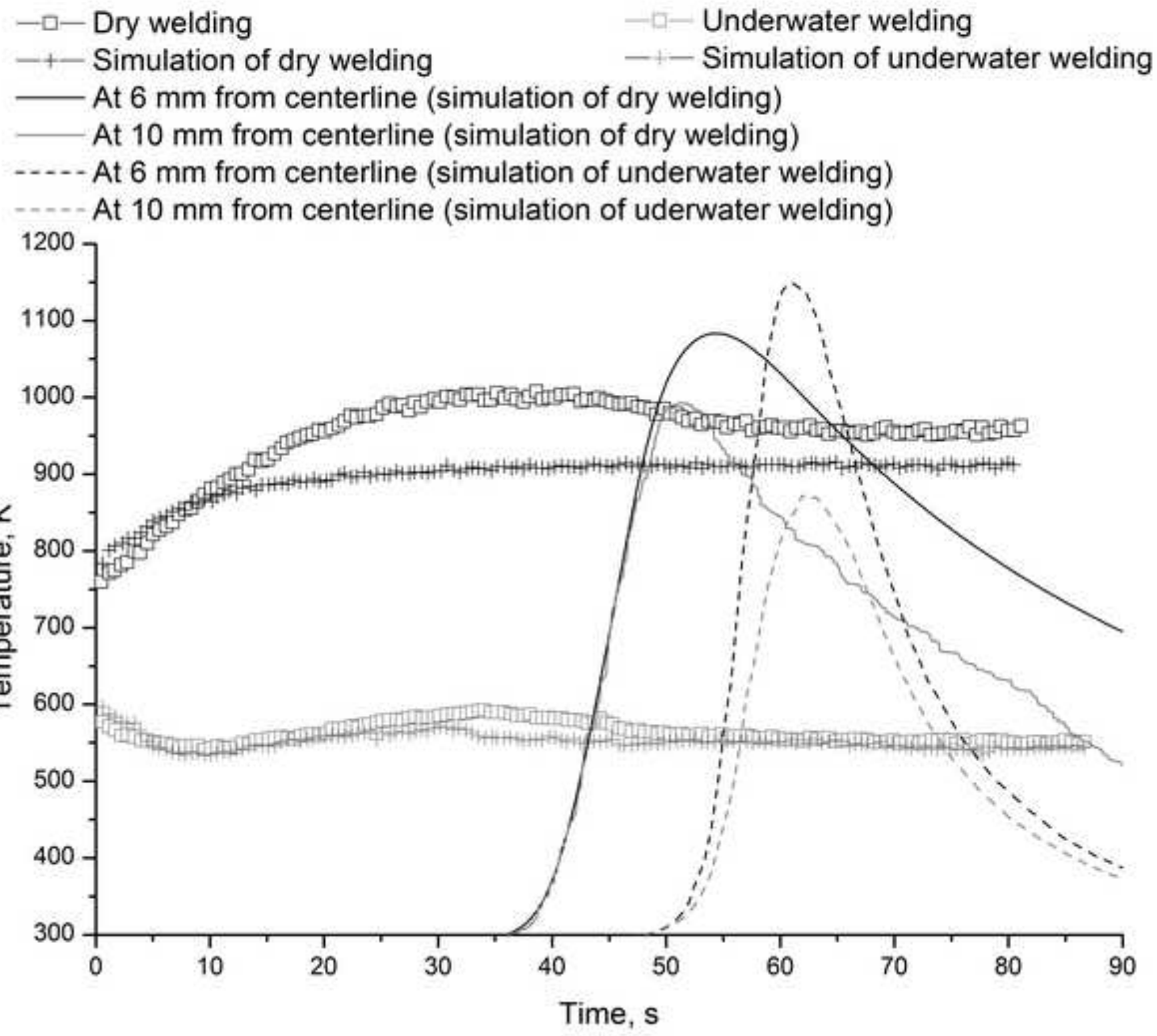




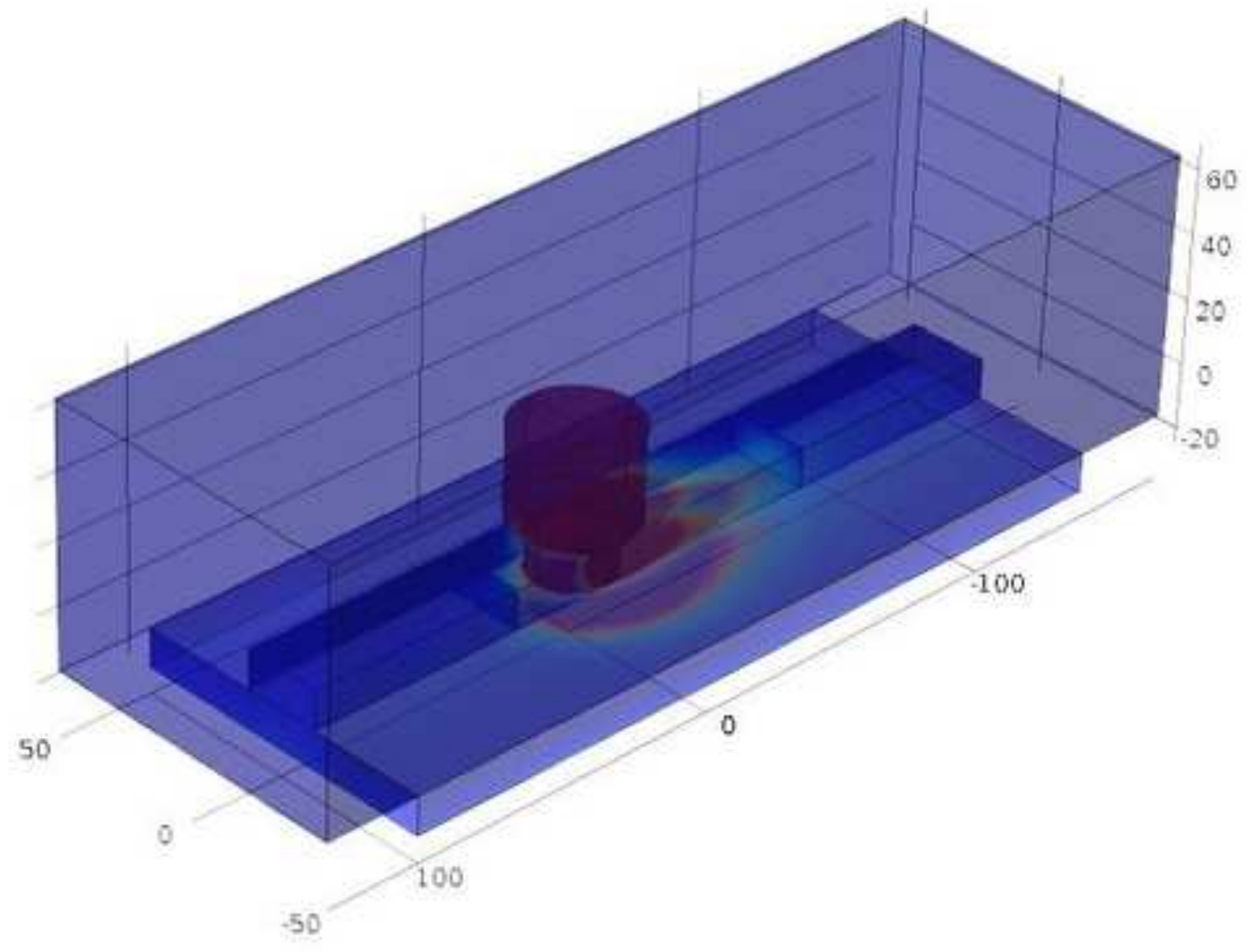

35

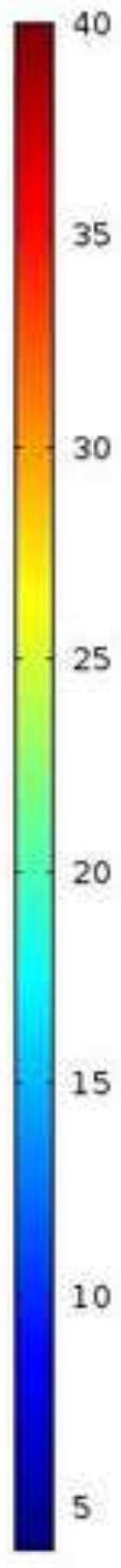


Table 1. Chemical composition of ISO 3183 X80M Steel.

\begin{tabular}{|l|l|l|l|l|l|l|l|l|l|l|l|l|l|l|l|}
\hline Element & $\mathrm{C}$ & $\mathrm{Si}$ & $\mathrm{Mn}$ & $\mathrm{P}$ & $\mathrm{S}$ & $\mathrm{V}$ & $\mathrm{Nb}$ & $\mathrm{Ti}$ & $\mathrm{Cu}$ & $\mathrm{Ni}$ & $\mathrm{Cr}$ & $\mathrm{Mo}$ & $\mathrm{Al}^{* *}$ & $\mathrm{~N}^{* *}$ & $\mathrm{~B}^{* *}$ \\
(wt. \%) & & & & & & & & & & & & & & \\
\hline $\mathrm{X} 80$ & 0.069 & 0.247 & 1.789 & 150 & 13 & 0.027 & 0.068 & 0.011 & 0.022 & 0.015 & 0.139 & 0.185 & 280 & 50 & 2 \\
\hline
\end{tabular}

${ }^{* *} \mathrm{ppm}$ 


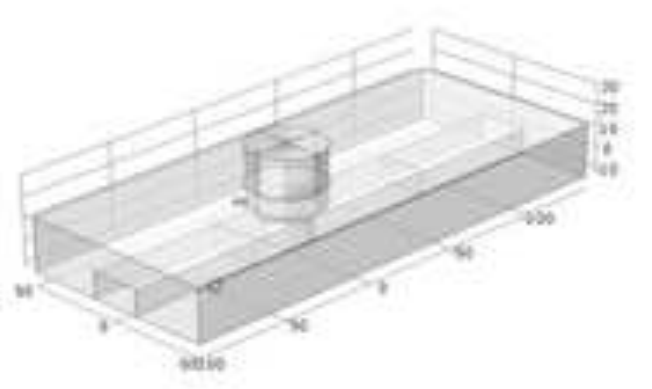

FSW

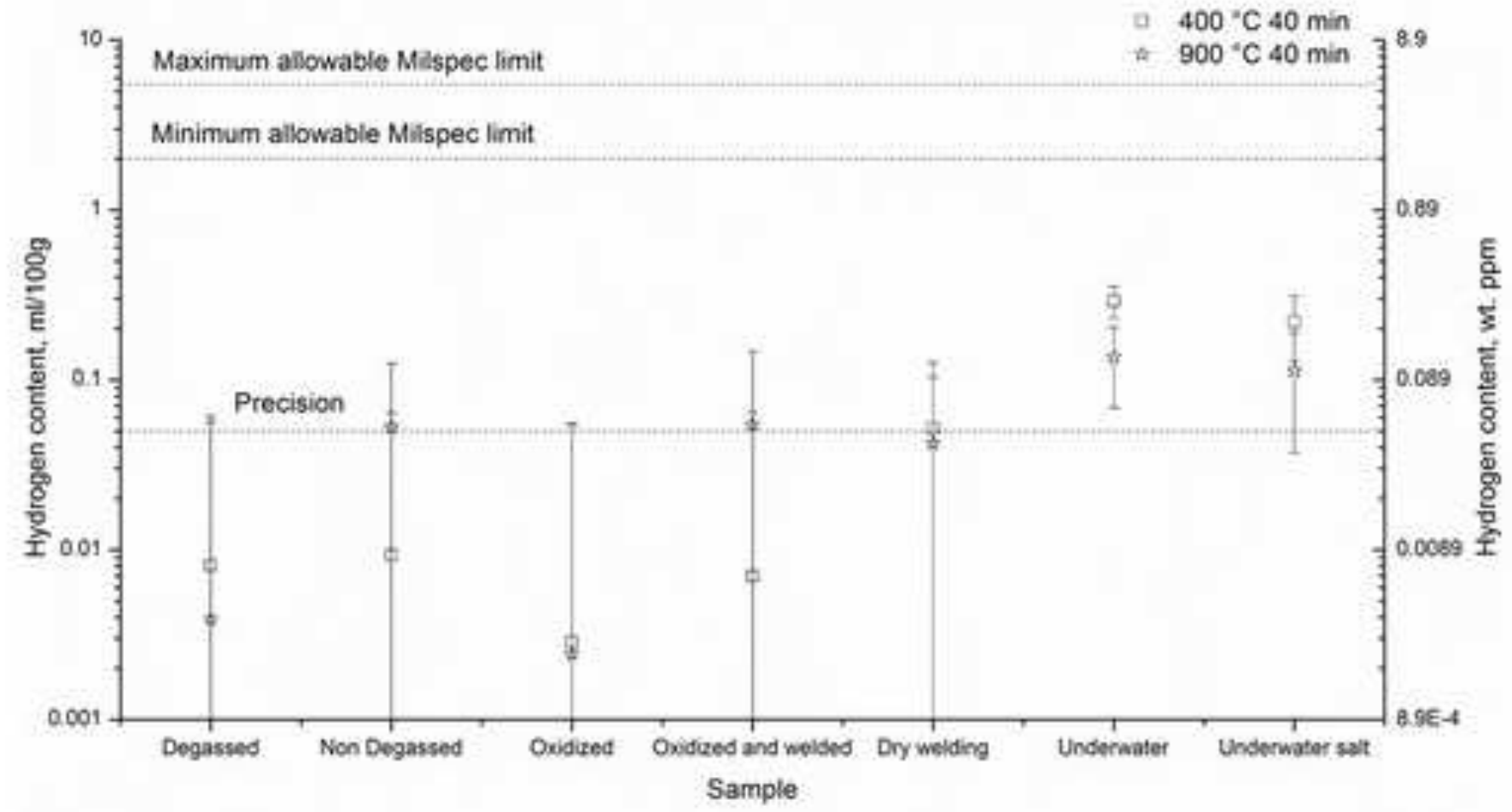

